\title{
Implementasi Metode TOPSIS untuk Rekomendasi dalam Menentukan Pengadaan Barang pada PT. Sentra Kemika Persada
}

\author{
Steven $^{1)}$, Vincent Setiawan ${ }^{2)}$, Halim Agung ${ }^{3)}$ \\ Teknik Informatika, Fakultas Teknologi dan Desain, Universitas Bunda Mulia \\ Jalan Lodan Raya No.2, Pademangan, Jakarta Utara, 14430 \\ 1)Email: stevennvirgo@gmail.com \\ 2)Email:vincoolzzz@gmail.co \\ ${ }^{3)}$ Email: hagung@bundamulia.ac.id
}

\begin{abstract}
PT. Sentra Kemika Persada is a company engaged in chemicals. PT. Sentra Kemika Persada is one of the importers and distributors of chemicals in Indonesia. So far, the decision to procure chemical goods at PT. Sentra Kemika Persada is still done manually, which is only by estimating the need for procurement of goods in the future without a clear or approximate calculation. In addition, checking the stock in the warehouse is still done manually, so it is difficult to get real time inventory reports and determine when PT. Sentra Kemika Persada must procure chemicals. The algorithm used in this study is TOPSIS with an accuracy rate of $75 \%$ and an error rate of $25 \%$
\end{abstract}

Keywords: inventory, procurement, PT. Sentra Kemika Persada, stock, TOPSIS

\begin{abstract}
Abstrak: PT. Sentra Kemika Persada adalah sebuah perusahaan yang bergerak di bidang bahan kimia. PT. Sentra Kemika Persada merupakan salah satu importir dan distributor bahan kimia di Indonesia. Selama ini, keputusan untuk pengadaan barang bahan kimia di PT. Sentra Kemika Persada masih dilakukan secara manual, yaitu hanya dengan memperkirakan kebutuhan pengadaan barang di masa depan tanpa perhitungan yang jelas atau dengan perkiraan semata. Selain itu, pengecekan stok barang di gudang masih dilakukan secara manual, sehingga sulit untuk mendapatkan laporan stok barang yang realtime dan menentukan kapan PT. Sentra Kemika Persada harus melakukan pengadaan barang bahan kimia. Algoritma yang digunakan dalam penelitian ini adalah TOPSIS dengan tingkat akurasi sebesar $75 \%$ dan tingkat kesalahan sebesar $25 \%$
\end{abstract}

Kata Kunci: laporan stok, pengadaan, PT. Sentra Kemika Persada, stok, TOPSIS

\section{PENDAHULUAN}

Dengan kemajuan ilmu pengetahuan dan teknologi yang sangat pesat, kebutuhan akan informasi menjadi salah satu hal yang sangat penting pada era globalisasi ini. PT. Sentra Kemika Persada selama ini tidak memiliki pedoman maupun perhitungan yang jelas dalam memperkirakan pengadaan barang di masa yang aka datang.

Permasalahan diatas dapat kami atasi dengan implementasi sistem penunjang keputusan yang memiliki sejumlah kriteria yang menjadi dasar untuk keputusan pengadaan barang bahan kimia di PT. Sentra Kemika Persada. Sistem ini dapat menjadi sumber referensi dan dasar pertimbangan bagi pimpinan PT. Sentra Kemika Persada untuk memutuskan waktu yang sangat tepat untuk melakukan pengadaan barang bahan kimia.

\section{METODE PENELITIAN}

Aplikasi ini dirancang dan dibangun dengan metodologi pengembangan sistem informasi menggunakan metode Waterfall. Yang meliputi beberapa proses di antaranya: 1) Analisis Kebutuhan. Pada tahapan ini akan dicari kebutuhan apa saja yang diperlukan untuk membangun sistem, seperti kriteria apa saja yang biasa digunakan dalam menentukan perlunya stok barang; 2) Desain Sistem. Pada tahapan ini akan dirancang bagaimana sistem bekerja mulai dari input hingga output serta interaksi user dengan sistem dan bisa diGambarkan dengan Flowchart Diagram; 3) Penulisan Kode Program. Bahasa Pemrograman yang digunakan untuk merancang aplikasi adalah PHP; 4) Pengujian. Pengujian akan dilakukan dengan mengubah berbagai jenis barang dengan jumlah stok yang bervariasi; dan 5) Pemeliharaan. Pemeliharaan 
yang akan dilakukan adalah dengan memperbaiki bug jika kedepannya ditemukan dan akan ditambahkan daftar barang yang baru jika ada.

TOPSIS didasarkan pada konsep dimana alternatif terpilih yang terbaik tidak hanya memiliki jarak terpendek dari solusi ideal positif, tetapi juga memiliki jarak terpanjang dari solusi ideal negatif [1] [2][3]. Pada dasarnya, proses pengambilan keputusan adalah memilih suatu alternatif. Konsep ini banyak digunakan pada beberapa model MADM (Multiple Attribute Decision Making) karena konsepnya sederhana dan mudah dipahami, komputasinya efisien, dan memiliki kemampuan untuk mengukur kinerja alternatif.

Rating kinerja setiap alternatif A1 pada setiap kriteria $\mathrm{C} 1$ yang ternormalisasi, seperti rumus 1 .

$$
\mathrm{r}_{i j}-\frac{x_{i j}}{\sqrt{\sum_{i=1}^{m} x_{i j}^{2}}}
$$

$$
\text { dengan } i=1,2, \ldots, m \text { dan } j=1,2, \ldots, n
$$

Rumus 1 Euclidean Length of a Vector [4][5]

Solusi ideal positif dan solusi ideal negatif dapat ditentukan berdasarkan rating bobot ternormalisasi(y), seperti rumus 2 .

$$
\begin{aligned}
& y_{i j}=w_{i j} r_{i j} \\
& A^{+}=\left(y_{1}^{+}, y_{2}^{+}, \ldots, y_{n}^{+}\right) \\
& A^{+}=\left(y_{1}, y_{2}, \ldots, y_{n}\right) \\
& \quad \text { dengan } \mathrm{i}-1,2, \ldots, \text { m dan } \mathrm{j}-1,2, \ldots, \mathrm{n} \\
& \text { Dengan }
\end{aligned}
$$

$$
\begin{aligned}
& y_{j}^{+}=\left\{\begin{array}{l}
\max y_{i} ; \text { jika jadalahatribut keuntungan } \\
\min y_{t} ; \text { jika jadalahatrihut biaya }
\end{array}\right. \\
& y_{j}^{-}=\left\{\begin{array}{l}
\min y_{i} ; j i k a j \text { jadalahatributkeuntungan } \\
\max _{i} y_{n} ; \text { jka jadalahatrihutbuaga }
\end{array}\right.
\end{aligned}
$$

Rumus 2 Menentukan nilai maksimal dan minimal.[6][7]

Jarak antara alternatif Ai dengan solusi ideal positif dirumuskan sebagai, seperti rumus $3[8][9]$.

$$
D_{i}^{+}=\sqrt{\sum_{j-i}^{n}\left(y_{i}^{+}-y_{j}\right)^{2}}
$$

Rumus 3 Menentukan jarak antara alternatif dengan solusi ideal positif

Jarak antara alternatif Ai dengan solusideal negatif dirumuskan sebagai, seperti rumus 4 .

$$
D_{i}^{-}=\sqrt{\sum_{j=i}^{n}\left(y_{i}-y_{i}^{-}\right)^{2}}
$$

Rumus 4 Menentukan jarak antara alternatif dengan solusi ideal negatif

Nilai preferensi untuk setiap alternatif (Vi) diberikan seperti rumus 5[10][11].

$$
\begin{aligned}
& V_{i}=\frac{D_{i}^{+}}{D_{i}^{*}+D_{i}^{*}} \\
& \text { Dimana : } \\
& r_{y} \quad=\text { Ranking kinerja alterntif ke-i } \\
& \text { pada kriteria ke-j. } \\
& x_{i} \quad \text { - Alternatif ke-i pada kriteria ke-j. }
\end{aligned}
$$

\section{HASIL DAN PEMBAHASAN}

Kebutuhan fungsional adalah jenis kebutuhan yang berisi proses-proses apa saja yang bisa terdapat dalam suatu sistem yang akan digunakan oleh pengguna. Kebutuhan fungsional dari aplikasi yang dirancang ini adalah sebagai berikut: Aplikasi dapat memberikan rekomendasi barang yang harus di stok berdasarkan nilai dari tiap kriteria; Aplikasi dapat menyimpan data atau record nama barang; Aplikasi dapat menampilkan data atau record berdasarkan periode; dan Rekomendasi stok barang menggunakan algoritma TOPSIS dapat memberikan hasil nilai yang akurat untuk pengambilan keputusan.

Flowchart diagram TOPSIS dalam menentukan pengadaan barang seperti pada Gambar 1.

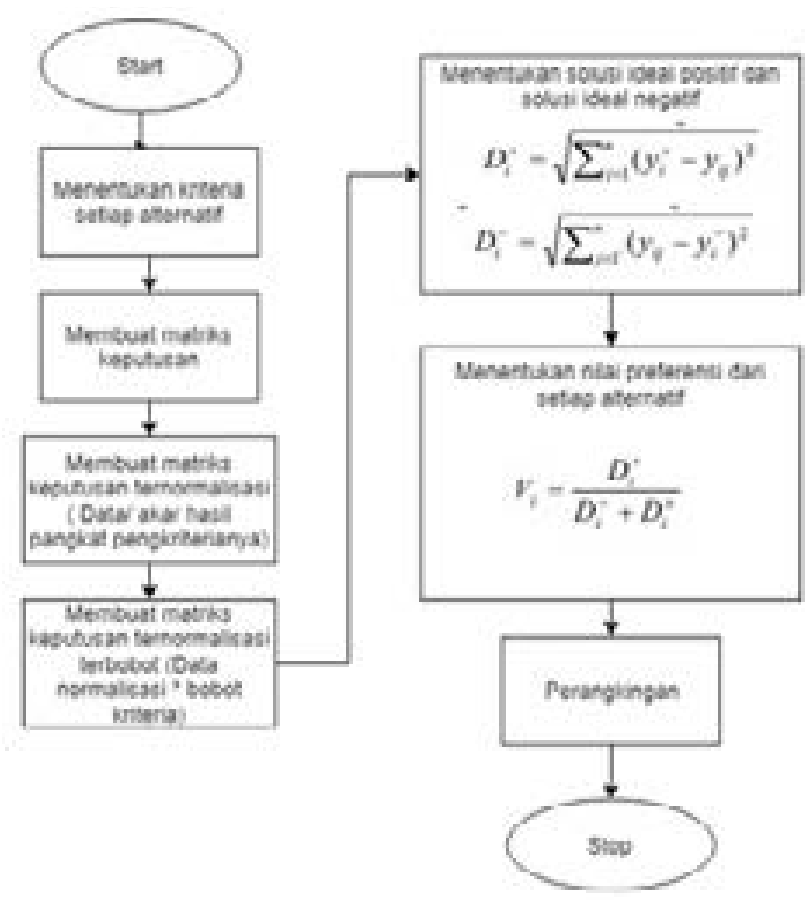

Gambar 1 Flowchart diagram TOPSIS 
Berdasarkan perhitungan TOPSIS tersebut maka di dapatkan hasil seperti pada Gambar 2.

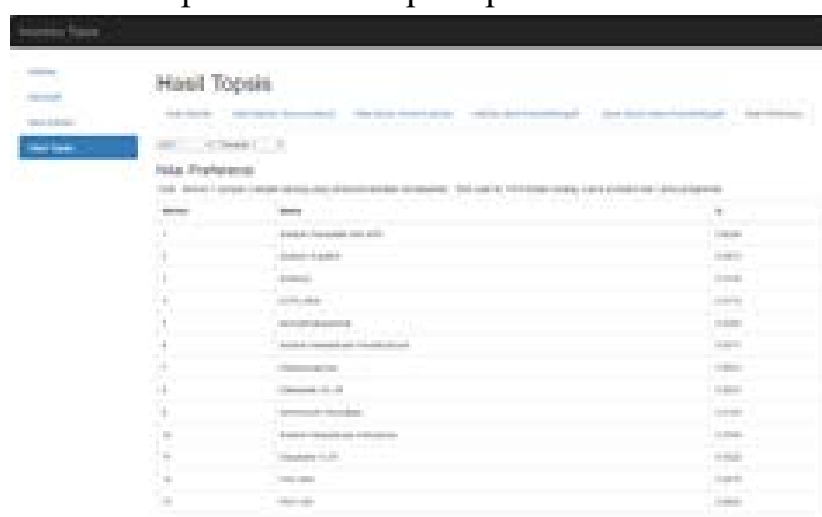

Gambar 2 Hasil triwulan 1

Pada triwulan 1 tahun 2017, hasil pengujian rekomendasi barang menunjukan tidak ada perbedaan barang dalam perekomendasian dan barang yang sebenarnya di stok oleh perusahaan.

Setelah itu, pengujian dilanjutkan dengan menguji setiap kriteria pada periode Triwulan 22017 seperti pada Gambar 3.

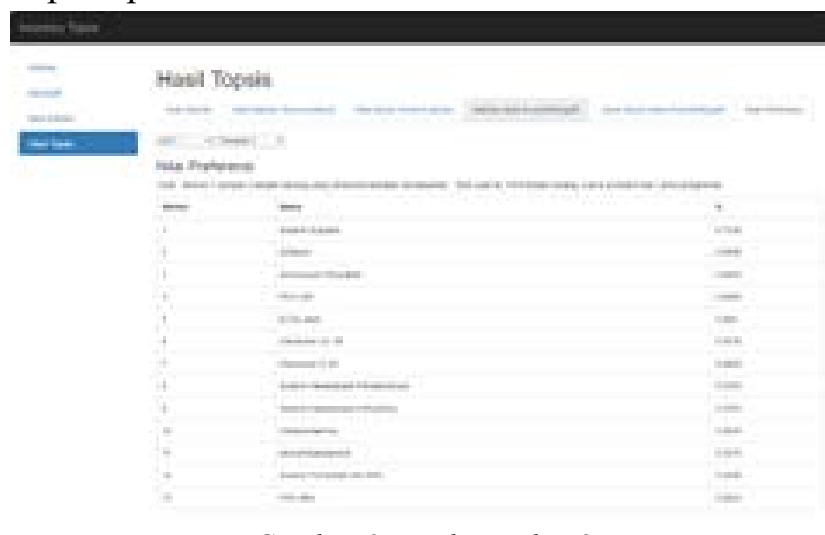

Gambar 3 Hasil triwulan 2

Pada triwulan 2 tahun 2017, hasil pengujian rekomendasi barang menunjukan tidak ada perbedaan barang dalam perekomendasian dan barang yang sebenarnya di stok oleh perusahaan.

Setelah itu, pengujian dilanjutkan dengan menguji setiap kriteria pada periode Triwulan 32017. Seperti pada Gambar 4.

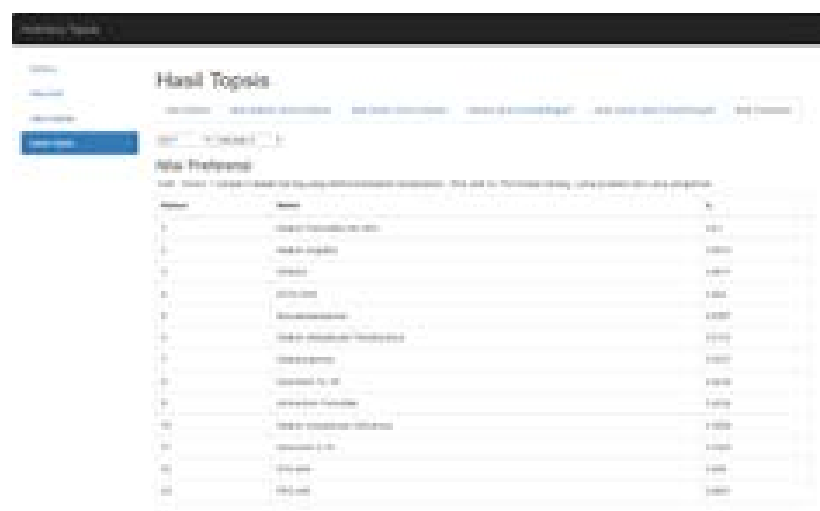

Gambar 4 Hasil triwulan 3
Pada periode triwulan 3 terdapat 1 perbedaan dengan hasil perhitungan TOPSIS, yaitu barang Ammonium Persulfate tidak di stok ulang oleh perusahaan.

Setelah itu, pengujian dilanjutkan dengan menguji setiap kriteria pada periode Triwulan 4 tahun 2017. Seperti pada Gambar 5

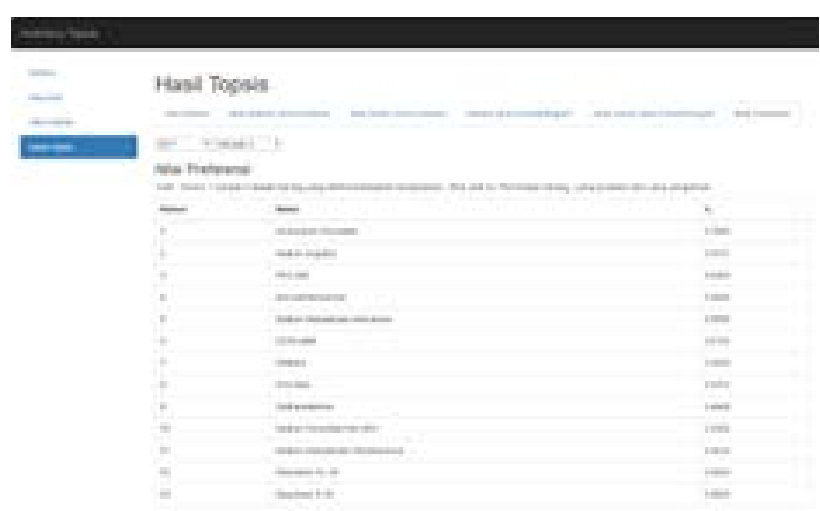

Gambar 5 Hasil triwulan 3

Pada periode triwulan 4 terdapat 4 perbedaan dengan hasil perhitungan TOPSIS, yaitu barang Sodium Persulfate Min.99\%, Sodium Sulphite, EDTA-4NA, Monoethanolamine tidak di stok ulang oleh perusahaan.

\section{SIMPULAN}

Berdasarkan hasil penelitian ini, dapat disimpulkan beberapa hal mengenai Implementasi Metode TOPSIS untuk Rekomendasi dalam Menentukan Pengadaan Barang pada PT. Sentra Kemika Persada: Hasil yang diambil untuk rekomendasi adalah nomor 1 sampai 5 pada nilai preferensi; Hasil pengujian kami menunjukkan tingkat akurasi sebesar 75\% dengan kecocokan 100\% pada triwulan $1,100 \%$ pada triwulan $2,80 \%$ pada triwulan 3, dan $20 \%$ pada triwulan 4; Hasil pengujian terdapat kesalahan sebesar $25 \%$ dengan komposisi $0 \%$ di triwulan $1,0 \%$ di triwulan $2,20 \%$ di triwulan 3, dan $80 \%$ di triwulan 4; dan Aplikasi kami dapat digunakan untuk merekomendasikan pengadaan stok barang pada PT. Sentra Kemika Persada karena memiliki kecocokan sebesar $75 \%$ dengan data asli perusahaan, namum perlu dilakukan pengembangan lebih lanjut agar tingkat akutasi program kami semakin baik.

\section{DAFTAR RUJUKAN}

[1] R. Fadhil., M. S. Maarif., T. Bantacut., \& A. Hermawan. SISTEM PENUNJANG KEPUTUSAN MULTI KRITERIA UNTUK PENGEMBANGAN 
AGROINDUSTRI KOPI GAYO MENGGUNAKAN PENDEKATAN FUZZY-ECKENRODE DAN FUZZY-TOPSIS. Jurnal Teknologi Industri Pertanian, Vol. 27. No. 1. 2017. Hal.103-113. ISSN 0216- 3160, EISSN 2252-3901.

[2] A. A. Sembiring., A. S. Sembiring., \& S. R. Siregar. SISTEM PENDUKUNG KEPUTUSAN PENENTUAN PRIORITAS PENGEMBANGAN INDUSTRI KECIL MENENGAH DI KABUPATEN KARO MENGUNAKAN METODE TOPSIS. Majalah Ilmiah INTI, Volume 13, Nomor 2. 2018. ISSN 2339210X.

[3] S. Rofiah. SELEKSI PENERIMAAN CALON MANAJER MENGGUNAKAN FUZZY-TOPSIS PADA PT. SAMAFITRO. Information Management For Educators And Professionals Vol.1, No. 1. 2016. E-ISSN: 2548-3331.

[4] D. R. Sari., A. P. Windarto., D. Hartama., \& Solikhun. SISTEM PENDUKUNG KEPUTUSAN UNTUK REKOMENDASI KELULUSAN SIDANG SKRIPSI MENGGUNAKAN METODE AHP-TOPSIS. Jurnal Teknologi dan Sistem Komputer, 2018, 1-6. e-ISSN:2338-0403.

[5] B. Agustian., \& O. Wibowo. PERANCANGAN SISTEM PENUNJANG KEPUTUSAN PEMILIHAN ANAK ASUH MENGGUNAKAN METODE TECHNIQUE FOR OTHERS REFERENCE BY SIMILARITY TO IDEAL SOLUTION (TOPSIS) PADA LAZ SEJAHTERA UMMAT. Jurnal Informatika Universitas Pamulang, Vol. 3, No.2, Juni 2018. ISSN 2541-1004

[6] B. Sodhi, Prabhakar, T. V. A SIMPLIFIED DESCRIPTION OF FUZZY TOPSIS. Dept. of Computer Science and Engineering, IIT Kanpur, UP 208016 India, 2017. arXiv:1205.5098v2.
[7] R. Govindaraju., M. I. Akbar, L. Gondodiwiryo \& Tota Simatupang. THE APPLICATION OF A DECISIONMAKING APPROACH BASED ON FUZZY ANP AND TOPSIS FOR SELECTING A STRATEGIC SUPPLIER. J. Eng. Technol. Sci., Vol. 47, No. 4, 2015, 406-425. ISSN: 2337-5779.

[8] G. S. Anaokar., A. K. Khambete., \& R. A. Christian, EVALUATION OF A PERFORMANCE INDEX FOR MUNICIPAL WASTEWATER TREATMENT PLANTS USING MCDM - TOPSIS. International Journal of Technology. 2018, 4: 715-726. ISSN 20869614.

[9] M. Zulqarnain., \& F. Dayan, SELECTION OF BEST ALTERNATIVE FOR AN AUTOMOTIVE COMPANY BY INTUITIONISTIC FUZZY TOPSIS METHOD. International Journal Of Scientific \& Technology Research Volume 6, Issue 10, October 2017. ISSN 2277-8616.

[10] C. Sun, Y. Xiang, S. Jiang \& Q. Che. A SUPPLY CHAIN RISK EVALUATION METHOD BASED ON FUZZY TOPSIS. C. Sun et al., Int. J. of Safety and Security Eng., Vol. 5, No. 2. 2015. 150-161. ISSN: 2041-9031.

[11] I. G. T. Isa, \& G. P. Hartawan. PERANCANGAN APLIKASI KOPERASISIMPANPINJAMBERBASIS WEB (STUDI KASUS KOPERASI MITRA SETIA). Universttas Muhammadiyah Sukabumi. Vol. 5 Edisi 10, Mar 2017. ISSN : 2088-6969 